\title{
How do reproductive age women perceive breast cancer screening in Ethiopia? A qualitative study
}

\author{
Feleke Doyore Agide ${ }^{1,2}$, Gholamreza Garmaroudi ${ }^{3}$, Roya Sadeghi ${ }^{3}$, Elham Shakibazadeh ${ }^{3}$, \\ Mehdi Yaseri ${ }^{4}$, Zewdie Birhanu Koricha ${ }^{5}$
}

1. Department of Health Education and Promotion, School of Public Health, International Campus, Tehran University of Medical Sciences, Tehran, Iran.

2. Department of Public Health officer, College of Medicine and Health Sciences, Wachemo University, Hossana, Ethiopia.

3. Department of Health Education and Promotion, School of Public Health, Tehran University of Medical Sciences, Tehran, Iran.

4. Department of Epidemiology and Biostatistics, School of Public Health, Tehran University of Medical Sciences, Tehran, Iran.

5. Department of Health, Behavior and Society, Institute of Health Sciences, Jimma University, Jimma, Ethiopia.

\section{Emails:}

feledoag@yahoo.com; feledoag@yahoo.com; garmaroudi@tums.ac.ir, sadeghir@tums.ac.ir, elham50sh@yahoo.com; m.yaseri@gmail.com; zbkoricha@yahoo.com

\begin{abstract}
Background: Breast cancer remains one of the deadliest non-communicable diseases in the world. In Ethiopia, breast cancer accounts for $33.4 \%$ of total cancer diagnosis in women.

Objective: This study aims to explore perception about breast screening behavior among reproductive age women.

Methods: This qualitative study was conducted as a baseline to identify gaps to design interventions that will enhance breast screening uptake among reproductive age women. Six focus group discussions and 9 in-depth interviews were conducted with women and health workers respectively. Semi-structured questions were used. Data analysis was analyzed by Atlas.ti. 7 and the ideas were put in direct quotation and narration.

Results: Lack of awareness is the preceding problem for self-susceptibility to breast cancer as well as for having breast screening. Majority of women thought that the cause of breast cancer was a sin (supernatural power). Self-efficacy and cues to action were the most important correlates of the perception owing to fear of socio-cultural stigma and discrimination.

Conclusion: All health belief model constructs identified a critical problem for adaptation of behavior. Therefore, this gives the opportunity to design and develop community-based intervention and explore new intervention mechanism with an accurate method.
\end{abstract}

Keywords: Behavior, breast, perception, qualitative data, Ethiopia.

DOI: https://dx.doi.org/10.4314/ahs.v19i4.22

Cite as: Agide FD, Garmaroudi G, Sadeghi R, Shakibazadeh E, Yaseri M, Koricha ZB. How do reproductive age women perceive breast cancer screening in Ethiopia? A qualitative study. Afri Health Sci.2019;19(4):3009-3017. bttps://dx.doi.org/10.4314/abs. v19i4.22

\section{Corresponding author:}

Gholamreza Garmaroudi,

Department of Health Education and Promotion,

School of Public Health, Tehran University of Medical

Sciences, Poursina Ave., Enghelab SQ., P.O. Box.

1417613151, Tehran, Iran, Tel: +98 2188989128,

Fax: +98 21 42933072; Email: garmaroudi@tums.ac.ir

\section{Introduction}

Breast cancer remains one of the deadliest non-communicable diseases in the world. Ethiopia is one of the countries with highest breast cancer burden and faces the challenges from its devastating effects in terms of morbidity and mortality ${ }^{1}$. According to the National Cancer Registry report of Ethiopia, it accounts $33.4 \%$ of total cancer diagnosis in women ${ }^{1,2}$.

(C) 2019 Agide et al. Licensee African Health Sciences. This is an Open Access article distributed under the terms of the Creative commons Attribution License (https://creativecommons.org/licenses/BY/4.0), which permits unrestricted use, distribution, and reproduction in any medium, provided the original work is properly cited. 
Worldwide breast cancer prevention strategies include early detection, mammography use, breast self-examination and clinical examination ${ }^{3}$. Low-income countries like Ethiopia need to implement a similar approach that guarantees access to early detection and treatment ${ }^{2-4}$.

Despite a drastic improvement in disease prevention as a result of the implementation of health extension program, the burden of breast cancer remains unacceptably high in Ethiopia. The poor health seeking behavior for cancer screening has made achieving WHO target difficult; and late stage reporting and severity is still a prob$\mathrm{lem}^{2,5}$.
Evidence from various studies indicate that outcome of cancer treatment largely depends on early screening ${ }^{6-10}$. Indeed, studies have not been conducted or limited so far on the perception of breast screening uptake among reproductive age groups in Ethiopia. For this, models are important guiding tools for the development of conceptual frameworks. This study used health belief model HBM which beliefs individuals' perceived susceptibility to and severity of a disease forced to shift weight of balance between perceived benefits and barriers ${ }^{11,12}$. Therefore, this study aims to explore perception about breast screening among reproductive age women using theoretical framework of the HBM See figure 1.

\section{BC ill health perception Modifying factors Likelihood of BC screening Behavior}

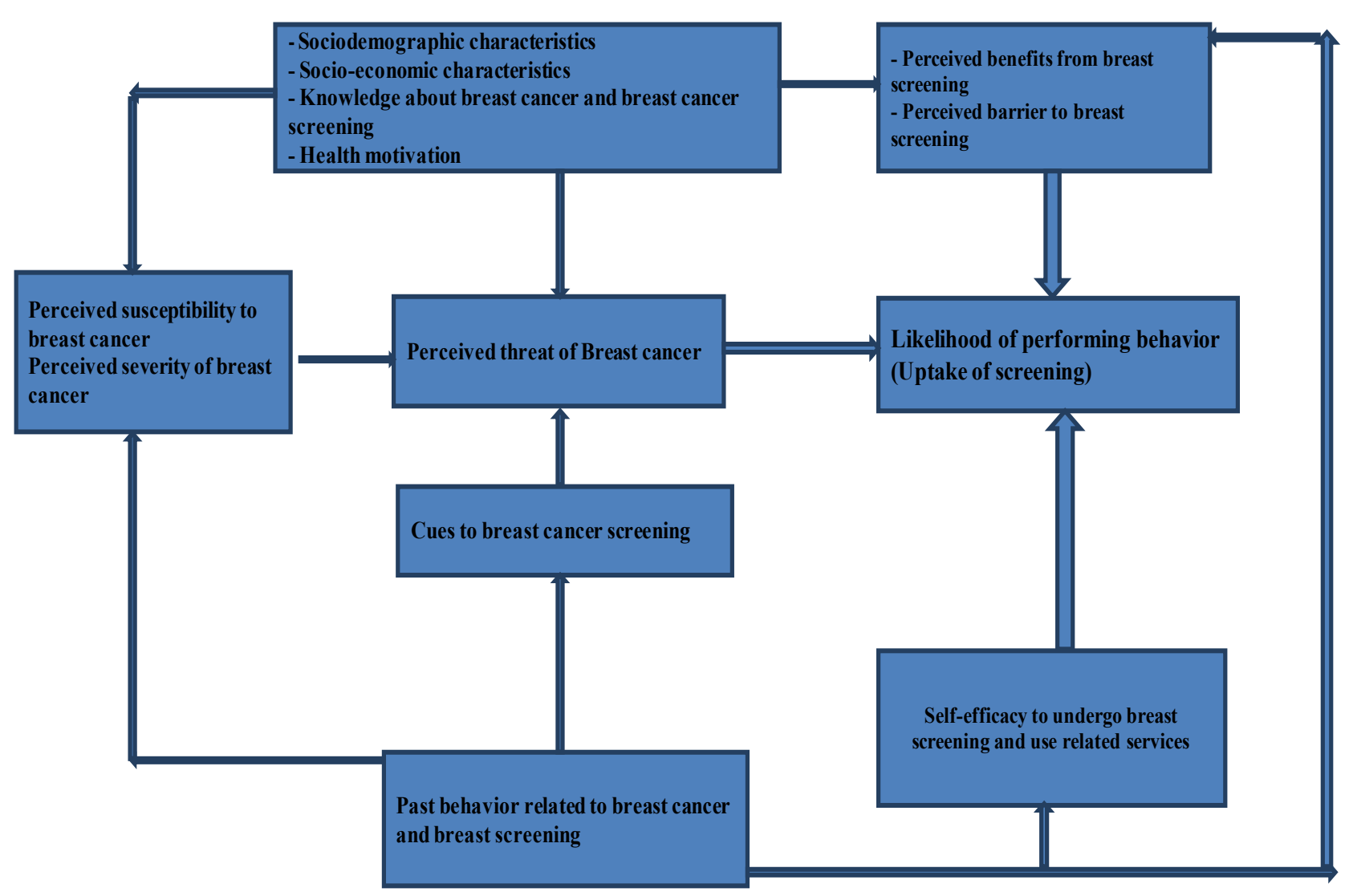

Fig 1: Conceptual framework 


\section{Methods}

Study setting: This study was conducted in six districts of the Hadiya Zone. The zone has twelve districts. It is located $230 \mathrm{~km}$ South West from the capital city of Ethiopia. The study period was as of April to May 2018.

Study design and sample: A grounded theory was used as a study design. Six focus group discussions FGD and 9 indepth interviews were conducted with women and health workers respectively. Purposive criteria related sampling was used. Each FGD consists of 9-12 participants. The criteria for FGD participants' selection were mothers who applied all health extension packages, respected in the area, and being vanguards in health committee. Homogeneity was maintained by age to reduce sensitivity. The criteria for in-depth interview participants' selection were being health extension workers, supervisors and disease prevention and health promotion experts.

Data collection procedure: FGD was used to explore perception of women on breast screening. Each FGD was conducted by principal investigator. For FGD, semi-structured questions were used. FGD was audio recorded using voice recorder. Each FGD lasted 1 to 1.5 hours and took place in a private setting. Information depth was determined through reaching 'point of saturation.' In-depth interviews were conducted with health workers. To maintain the trust worthiness and validity of the findings, the researchers developed rapport with participants. Credibility/conformability was maintained through participant checking during FGDs and in-depth interview, and through feedback of findings at the end of the study from whom the information was obtained. Keeping a diary with information about impressions was enhanced conformability. Dependability was maintained through capturing the range and depth of responses through reaching 'saturation point'.
Data management and analysis procedures: The transcribed verbatim messages were translated from Amharic to English language. Prior to categorizing into different themes, we conceptualized perception of the women for breast screening in various ways owing to the screening behavior. First, breast screening is defined as an action taken for an early detection of breast cancer through breast self-examination, breast clinical examination and mammography use. Second, perception related to screening is defined as the perception towards breast cancer and its prevention. Later, these concepts were analyzed in various themes following the constructs of HBM. Then, themes emerged out and data analysis was done accordingly by Atlas ti. 7 software ${ }^{13}$. The results were presented by consolidated criteria for reporting qualitative research COREQ: a 32-item checklist for interviews and focus groups was used for reporting results ${ }^{14}$. The researchers undertook the whole research process from participant selection to publication of the results.

\section{Ethics}

Ethical approval was obtained from the Ethics Committee of Tehran University of Medical Sciences IR.TUMS. SPH.REC.1396.4088. All the study participants were given detailed information about the study and verbal consent was obtained before participation.

\section{Results}

\section{Socio-demographic characteristics of the partici- pants}

A total of 64 women were involved in six FGDs. The age of the participants ranged from 21 to 49 years. Accordingly, the majority of the participants were in the age range of 35-44 years and housewives Table 1. Nine in-depth interviews were conducted with health workers Table 2. 
Table 1. Socio-demographic characteristics of the FGD participants

\begin{tabular}{llll}
\hline Variables & Categories & Number & Percentage \\
Age & $15-24$ & 3 & 4.69 \\
& $25-34$ & 8 & 12.50 \\
& $35-44$ & 41 & 64.06 \\
Marital status & $45-49$ & 12 & 18.75 \\
Occupational status & Married & 53 & 82.81 \\
& Single & 11 & 17.19 \\
& House wife & 53 & 82.81 \\
Educational level & Gerchant & 7 & 10.94 \\
& Government & 4 & 6.25 \\
& Cannot read and & 36 & 56.25 \\
& write ran read and & 24 & 37.50 \\
& Can & & \\
& write & 3 & 4.69 \\
Place of Residence & Diploma & 1 & 1.56 \\
& First Degree & 53 & 82.81 \\
& Rural & 11 & 17.19 \\
\hline
\end{tabular}

Table 2. Socio-demographic characteristics of the in-depth interview participants

\begin{tabular}{llll}
\hline Variables & Categories & Number & Percentage \\
Age & $20-29$ & 4 & 44.45 \\
& $30-39$ & 3 & 33.33 \\
Sex & $40-49$ & 2 & 22.22 \\
& Male & 3 & 33.33 \\
Marital status & Female & 6 & 66.67
\end{tabular}

General breast health and health seeking behavior in terms of screening

Participants in the most rural area had very low awareness about their breast health and its screening. However, they heard of breast cancer. All the participants' agreed that breast health is the most important for their life. However, lack of awareness of breast health is a critical problem for adaptation of behavior.

\section{Perceived susceptibility to breast cancer}

The majority of participants perceived that the cause of breast cancer is a supernatural power and a few associated it with breast enlargement in childhood period. God/ Allah punishes sinners in different ways or "Setan" Devil might get those women in different deviated behavior including cheating on husband, curses from ancestors or going to witchcraft.

A 39 years old participant said, "As to me, doing good or bad acts will determine the occurrence of a disease. A good act leads to good health and a bad leads to disease.....as a spiritual woman, I believe like this..."
A few participants perceived that not breast feeding are the cause of the breast cancer. Most of the urban women left their child to the modern feeding system and go to their job.

A 29 years old urban participant said, "... Sometimes those women who were not breast feeding their child at early stage....their breast becomes very large and develop breast mass and later develops breast cancer..."

In general, participants had very low self-susceptibility to breast cancer but they claimed others as highly susceptible attaching with various social, cultural and religious factors such as sin, deviation from truth, cheating on husband, and multiple pregnancies.

A 27 years old female health worker said, "... As you know, our people are illiterate for many diseases including cancer. Indeed, most diseases become the issue of health offices after killing many. Health workers even believe in spiritual issues rather than being scientific. Personally, I knew the educated woman with breast cancer who usually went to spiritual prayer rather than taking medicine. 
Despite the cost of treatment for breast cancer is very high; the individual attempt to prevent the disease is very far from the truth."

All women from urban areas of Hossana town commonly thought that lack of awareness to seek early treatment to any symptoms on breast was a cause of breast cancer. One of the participants said, "... You know, we, women are mothers with a lot of responsibilities. .... Sometimes, even we do not care about our health and we cannot recognize what is happening on us. This in turn leads to have a worst condition and later develop diseases. Sometimes simple scabies will be developed to a large gangrene to be a cancer."

All health workers in their interview agreed that the recommendation for breast cancer screening varies all over the world. They also agreed that all age groups are susceptible for the diseases.

Another 22 years educated participant said, "...I heard breast cancer occurs in the later age but the reverse is true in our zone that majority of the breast cancer patients are young and in my age. Since the specific time or age category for occurrence of breast cancer is not known, as to me, it is better to set policies and education for all age groups."

\section{Perceived severity of breast cancer}

All the participants' agreed on the seriousness of the problem without reservation.

A 22 years old woman said, "... I think it is common to all of us to perceive breast cancer as it is not curable disease. Since the treatment for cancer is found outside the country, it is not affordable and the only option is death. For the question you asked as "do women prefer to use screening as primary prevention methods?” In my opinion, I don't think so; in fact, if they had been told to use affordable screening methods, they might have been engaged in prevention but it needs intensive work."

A 42 years old woman said, "The severity of the breast cancer is unquestionable... Women prefer to die with gunshot than breast cancer." All the participants within the group supported this idea.

\section{Perceived benefits of screening and health seeking behavior through screening methods}

All FGD and in-depth interview participants said that women preferred traditional medicine than modern one. A 47 years old participant said, “...women prefer traditional bealer to get fast relief and recovery from their problem and for the time being it gives some relief but it does not cure."
Concerning breast screening, almost all the participants commonly believed that they had not performed breast self-examination. However, a few heard of breast self-examination and breast clinical examination as well as mammography use.

A 41 years old health worker said, "I am quite sure that women do not perform breast self-examination nor seek clinical examination and mammography. However, they might see their breast mass and consider it as gangrene or scabies or they might see and left it as it is."

In parallel speaking, a few participants agreed that they sometimes check their breast but not in regularly recommended period. Regarding breast clinical examination, all health workers and women agreed that going to hospital to check breast is unusual in our culture and society. However, those women in critical condition might see doctor in uncontrollable stage.

A 33 years old participant said, "... Going to health institution is the question of the mothers or women who get breast diseases manifested with signs and symptoms like enlargement of breast with pus and abscess. I knew women who are going to hospital after seriously ill with breast cancer but died. In some cases, for instance, if there is any smelling, they will not go to hospital until they become bedridden."

The participants were commonly agreed that mammography use for poor is not affordable. Indeed, mammography is found in the central part of Ethiopia in limited governmental and a few private hospitals.

A 43 years old educated participant said, "Personally, I believe that women do not know mammography by name and type nor associated with breast cancer screening. However, they might see in hospitals. I am sure that majority might not be exposed for it."

In parallel speaking, very few participants from the urban parts believed that seeing doctor on an early stage and recognizing oneself in recommended period through mammography and/or self-examination is effective in preventing the diseases. Health workers in their interview supported this idea.

A 39 years old participant from Hossana town said, "... Women who trusted in God and spray the "prayed water" Yetetseleyebet wuba by prophets healed the women who developed such a disease." Another 32 years old participant from the same group said, ".... In fact, this is true in our church Orthodox, those women who believed in God with their full heart go to 'Tsebel' Holy water and then healed after drinking and spraying it by church boly person." 


\section{Perceived barriers for breast screening}

All FGD and in-depth interview participants commonly believed that there are various factors that affect the screening behavior of the women such as socio-cultural, economic, and environmental, and knowledge and perception of the diseases. The two major factors were low awareness and the costly nature of the services. The vast majority of the participants believed that deviation from the socio-cultural and spiritual law could be the cause of the diseases.

A 49 years old woman said, "...our ancestors advised us... you might break the rule of the father, mother, and the relatives but don't pass the law of God, therefore, you will die. Even, you would be ashamed to express your pain due to this spiritual curse..."

All health workers believed that unacceptable social values and norms are the other barrier of the participants not to disclose their problem and to have breast screening.

\section{Self-efficacy of the women for using breast screen- ing}

Self-efficacy was the most important correlates of the perception. Most of the participants' self-efficacy towards breast self-examination is very high. All rural areas women commonly thought that once we know how to perform self-examination, it could be our job for ever. Self-efficacy of the women for mammography use very low due to the cost required for the services. Likewise, the self-efficacy for breast clinical examination is unexpectedly low; however, breast biopsy was there in zonal and district hospitals.
A 28 years old participant from Misha district said, “... In my opinion, once you empower women with various factors like awareness creation, affordability, accessibility, and empowering them with health seeking behavior could be the best solution to capacitate them. If the government does these, I think most of them do have screening. ...you know breast self-examination is not treatment rather it leads a woman to worry about their breast health. As to me, breast self-examination is effective when all the screening services and treatment are there."

\section{Cues to action for breast cancer screening}

Accesses to services for social marketing and media were poor for a variety of psycho-social and cultural reasons. Majority of participants, including educated ones, were not exemplary in breast screening. Almost all the participants did not know women who were regularly checking their breast or using mammography and/or clinical examination.

A 40 years old health worker said, “....OPD health education and health information delivering team should bring the breast cancer cases to the hospital TV and should bring those individuals who were suffering with this disease."

A few participants reported they have seen patients who have been suffering from breast cancer.

A 48 years old participant said, "... I have seen a woman suffering from breast cancer. Her breast smelling makes anyone to know her disease. For me a good lesson/alarm to keep my breast health." Finally, we summarized each results with corresponding behavior based on HBM constructs see table 3 . 
Table 3: Summary of the results as per consolidated criteria for reporting qualitative research (COREQ): for interviews and focus groups was used for reporting results

\begin{tabular}{|c|c|c|c|}
\hline \multirow[t]{2}{*}{ HBM Constructs } & \multicolumn{3}{|l|}{ Expected behavior explored } \\
\hline & Breast self-examination & Breast clinical examination & Mammography Use \\
\hline $\begin{array}{l}\text { Perceived } \\
\text { susceptibility }\end{array}$ & They linked with breast cancer & They linked with breast cancer & They linked with breast cancer \\
\hline Perceived severity & They linked with breast cancer & They linked with breast cancer & They linked with breast cancer \\
\hline Perceived benefits & Linked with breast checkups & Linked with breast cancer screening methods & Linked with breast screening methods \\
\hline Perceived barriers & $\begin{array}{l}\text { Linked with social, behavioral, } \\
\text { environmental and misconception }\end{array}$ & $\begin{array}{l}\text { Linked with cost (boldly) social, behavioral, } \\
\text { environmental and misconceptions }\end{array}$ & $\begin{array}{l}\text { Linked with cost (boldly), affordability } \\
\text { and misconceptions }\end{array}$ \\
\hline Self-efficacy & $\begin{array}{l}\text { Linked with skills screening } \\
\text { methods awareness and reading } \\
\text { habit }\end{array}$ & $\begin{array}{l}\text { Linked with screening methods awareness, } \\
\text { accessibility and affordability }\end{array}$ & $\begin{array}{llr}\text { Linked with screening methods } \\
\text { awareness, accessibility } \\
\text { affordability } & & \\
& & \end{array}$ \\
\hline Cues to action & $\begin{array}{l}\text { Linked with accessibility of } \\
\text { information and media exposure } \\
\text { and reading habit as well as } \\
\text { recognition of symptoms }\end{array}$ & $\begin{array}{l}\text { Linked with hospital visit, health workers } \\
\text { contact, advice from literates, accessibility of } \\
\text { information and media exposure and reading } \\
\text { habit. }\end{array}$ & $\begin{array}{l}\text { Linked with hospital visit, health } \\
\text { workers contact and } \\
\text { advice, information accessibility and } \\
\text { exposure and reading habit. }\end{array}$ \\
\hline
\end{tabular}

\section{Discussion}

According to HBM, individuals' perceived susceptibility to and severity of a disease forced to shift weight of balance between perceived benefits and barriers. This in turn helps people to go through the healthier way provided that people are already aware of health threat under a basic assumption that people are motivated for their own health ${ }^{11,12}$.

This study found that there was a strong interplay between the perception and breast screening. Lack of awareness is a universal and preceding problem for low perceived susceptibility to breast cancer. The result is consistent with the findings of Ethiopia and other countries ${ }^{15-19}$. Similarly, other several studies also ascertained that the perception and knowledge of breast cancer and its prevention strategies were relatively good for urban areas ${ }^{15-17,20-22}$.

The concept of a cause of diseases and prevention preferences reported in our study was similar to findings from others ${ }^{21,23-25}$. This misconception might also be the result of very low awareness and a sense of not being vulnerable. This is similar with the assumption of HBM that states if individuals consider themselves as susceptible to a disease and believe that the condition would have potentially serious consequences and believe the anticipated benefits of taking action outweigh the barriers to action, they are likely to perform the breast screening. Hence, acknowledgement of susceptibility and severity provide the motivation to act ${ }^{11,12,25}$.

This study found that perceived benefits provided there are no barriers of screening provides a preferred course of action. Beliefs concerning the cause of the disease are a crucial determinant of subsequent screening. This is consistent with the study conducted in Addis Ababa ${ }^{21,26}$.

In this study, participants believed that breast cancer is a serious and often fatal disease. The result is consistent with the study conducted in Addis Ababa and other countries $^{21,26,27}$.

In this study, self-efficacy of the women for breast screening is very low. The cultural, religious and social discrimination were the main reasons. This is similar to the study conducted in Addis Ababa in cervical cancer that showed the total stigma and discrimination for cancer is high $^{28}$. The study explored that self-efficacy towards breast self-examination was relatively good for a few partici- 
pants. Similarly, self-efficacy is a predicting variable in several breast cancer studies ${ }^{15,19,23,24}$. It is also consistent with the assumption of HBM that people will engage on healthy behavior if they are confident to successfully undertake and cope with $i^{11,12}$. The socio-cultural, religious and health system barriers were the frequently mentioned problems for breast screening. This is similar to the study conducted in Africa, Asia and USA ${ }^{10,12,24,25}$.

In this study, the influence of media was very poor for a variety of psycho-social and cultural reasons. This is similar to the studies conducted using $\mathrm{HBM}^{6,10,12,24,25}$.

\section{Conclusion}

This study revealed that knowledge, perception and future intentions of the women to prevent breast cancer are the important determinants of breast screening. All HBM constructs had shown the important gap for future intervention. Despite the misconceptions related to the cause of breast cancer and its screening, the pattern of screening behavior alternated between natural breast self-examination and man-made methods mammography use and breast clinical examination. Therefore, breast cancer prevention programs must address socio-cultural and religious barriers, and health service factors that influence breast screening through appropriate behavioral change communication strategies. In our quest to understand better about the problem, further research is needed to assess whether the behaviors' analyzed here provide a complete picture of women's breast screening methods or not.

\section{Acknowledgements}

First and for most, we would like to thank all FGD and in-depth interview participants for providing all the important information. We would also like to acknowledge international campus of Tehran University Medical Sciences for partial funding of this study. We also thank Hadiya Zone Health Department for providing baseline information and for financial support.

\section{Funding}

This research is partially funded by international campus of Tehran university medical sciences with project numbers 9513489001-292293.

\section{Authors' contributions}

All authors designed the study. FDA, GG, RS and ZBK revised the manuscript and approved the final manuscript.

\section{Conflicts of interest}

The authors declared that they have no conflict of interest.

\section{References}

1. Tigeneh W, Molla A, Abreha A, Assefa M. Pattern of cancer in Tikur Anbessa specialized hospital oncology center in Ethiopia from 1998 to 2010. Int J Cancer Res Mol Mech. 2015;11.

2. Abate Y, Yilma Z, Assefa M, Tigeneh W. Trends of breast cancer in Ethiopia. Int J Cancer Res Mol Mech. 2016;2:1-5 PubMed .

3. Sankaranarayanan R, Ramadas K, Thara S, Muwonge $\mathrm{R}$, Prabhakar J, Augustine P, et al. Clinical breast examination: preliminary results from a cluster randomized controlled trial in India. Journal of the National Cancer Institute. 2011;10319:1476-80.

4. Yip C-H, Cazap E, Anderson BO, Bright KL, Caleffi M, Cardoso F, et al. Breast cancer management in middle-resource countries MRCs: consensus statement from the Breast Health Global Initiative. The Breast. 2011;20:S12-S9.

5. Birhane N, Mamo A, Girma E, Asfaw S. Predictors of breast self-examination among female teachers in Ethiopia using health belief model. Archives of Public Health. 2015;731:39.

6. Agide FD, Sadeghi R, Garmaroudi G, Tigabu BM. A systematic review of health promotion interventions to increase breast cancer screening uptake: from the last 12 years. European Journal of Public Health. 2018.

7. Agide FD, Garmaroudi G, Sadeghi R, Shakibazadeh E, Yaseri M, Koricha ZB, et al. A systematic review of the effectiveness of health education interventions to increase cervical cancer screening uptake. European Journal of Public Health. 2018;286:1156-62.

8. Engelman KK, Cupertino AP, Daley CM, Long T, Cully A, Mayo MS, et al. Engaging diverse underserved communities to bridge the mammography divide. BMC Public Health. 2011;111:47 PubMed .

9. Siegel R, Naishadham D, Jemal A. Cancer statistics, 2013. CA: A Cancer Journal for Clinicians. 2013;631:11-30.

10. Lu M, Moritz S, Lorenzetti D, Sykes L, Straus S, Quan H. A systematic review of interventions to increase breast and cervical cancer screening uptake among Asian women. BMC Public Health. 2012;121:413 PubMed .

11. Glanz K, Rimer BK, Viswanath K. Health behavior and health education: theory, research, and practice: John Wiley \& Sons; 2008. 
12. Hausmann-Muela S, Ribera JM, Nyamongo I. Health-seeking behaviour and the health system response. Disease Control Piroirities Project working paper No14. 2003.

13. Friese S. Qualitative data analysis with ATLAS. ti: Sage; 2014.

14. Tong A, Sainsbury P, Craig J. Consolidated criteria for reporting qualitative research COREQ: a 32-item checklist for interviews and focus groups. International Journal for Quality in Health Care. 2007;196:349-57.

15. Reeler A, Sikora K, Solomon B. Overcoming challenges of cancer treatment programmes in developing countries: a sustainable breast cancer initiative in Ethiopia. Clinical Oncology. 2008;202:191 PubMed -8.

16. Abay M, Tuke G, Zewdie E, Abraha TH, Grum T, Brhane E. Breast self-examination practice and associated factors among women aged $20-70$ years attending public health institutions of Adwa town, North Ethiopia. BMC Research Notes. 2018;111:622.

17. Moss SM, Cuckle H, Evans A, Johns L, Waller M, Bobrow L. Effect of mammographic screening from age 40 years on breast cancer mortality at 10 years' follow-up: a randomised controlled trial. The Lancet. 2006;3689552:2053-60.

18. Taymoori P, Molina Y, Roshani D. Effects of a randomized controlled trial to increase repeat mammography screening in Iranian women. Cancer Nursing. 2015;384:288. 19. Fry RB, Prentice-Dunn S. Effects of a psychosocial intervention on breast self-examination attitudes and behaviors. Health Education Research. 2005;212:287-95.

20. Arshad S, Williams KP, Mabiso A, Dey S, Soliman AS. Evaluating the knowledge of breast cancer screening and prevention among Arab-American women in Michigan. Journal of Cancer Education. 2011;261:135-8.

21. Legesse B, Gedif T. Knowledge on breast cancer and its prevention among women household heads in
Northern Ethiopia. Open Journal of Preventive Medicine. 2014;401:32.

22. Nguyen TT, Le G, Nguyen T, Le K, Lai K, Gildengorin $\mathrm{G}$, et al. Breast cancer screening among Vietnamese Americans: a randomized controlled trial of lay health worker outreach. American Journal of Preventive Medicine. 2009;374:306-13.

23. Eskandari-Torbaghan A, Kalan-Farmanfarma K, Ansari-Moghaddam A, Zarei Z. Improving breast cancer preventive behavior among female medical staff: the use of educational intervention based on health belief model. The Malaysian Journal of Medical Sciences: MJMS. 2014;215:44.

24. Tuzcu A, Bahar Z, Gözüm S. Effects of interventions based on health behavior models on breast cancer screening behaviors of migrant women in Turkey. Cancer Nursing. 2016;392:E40-E50.

25. Hajian S, Vakilian K, Najabadi KM, Hosseini J, Mirzaei HR. Effects of education based on the health belief model on screening behavior in high risk women for breast cancer, Tehran, Iran. Asian Pac J Cancer Prev. 2011;121:49-54.

26. Kebede AGG, Zewdneh D, Dellie S, Tequabo Y, Zenebe M. Knowledge about breast cancer risk-factors, breast screening method and practice of breast screening among female healthcare professionals working in governmental hospitals, Addis. PLoS ONE. 2015;104:e0125210.

27. Motilewa OO, Ekanem US, Ihesie CA. Knowledge of breast cancer and practice of self-breast examination among female undergraduates in Uyo, Akwa Ibom State, Nigeria. International Journal of Community Medicine and Public Health. 2017;24:361-6.

28. Birhanu Z, Abdissa A, Belachew T, Deribew A, Segni $\mathrm{H}$, Tsu $\mathrm{V}$, et al. Health seeking behavior for cervical cancer in Ethiopia: a qualitative study. International Journal for Equity in Health 2012, http:/ / www.equityhealthj.com/ content $/ 11 / 1 / 83$ 